Revista Destaques Acadêmicos, Lajeado, v. 13, n. 2, 2021. ISSN 2176-3070

DOI: http://dx.doi.org/10.22410/issn.2176-3070.v13i2a2021.2930

http://www.univates.br/revistas

\title{
UM CONTRATO E TRÊS GARANTIAS: EDUCAÇÃO, COMUNIDADE E DEMOCRACIA
}

\author{
Alana Zanatta Battisti ${ }^{1}$, Leila Viviane Scherer Hammes ${ }^{2}$
}

Resumo: A educação, a comunidade e a democracia são três elementos essenciais para a vida em sociedade. Por isso, o objetivo do artigo é averiguar a incidência dos princípios constitucionais educacionais, notadamente o da gestão democrática, no contrato de prestação de serviço celebrado pelo Município de Lajeado/RS e pela Universidade do Vale do Taquari - Univates. No que se refere à metodologia, a pesquisa tem natureza aplicada, abordagem qualitativa e, quanto ao objetivo, é exploratória. Para testar a sua verificabilidade, foi utilizado o método dedutivo, com o emprego de três técnicas: bibliográfica, documental e estudo de caso. $\mathrm{O}$ resultado do artigo confirmou a hipótese aventada no início da pesquisa, no sentido de que o contrato representa uma manifestação dos princípios constitucionais educacionais, destacadamente o da gestão democrática, porquanto aproxima a comunidade da administração da escola, tornando efetivo o direito à educação e fortalecendo o viés comunitário da universidade.

Palavras-chave: Direito à educação. Comunidade. Democracia. Prestação de serviço.

\section{Introdução}

Desde os tempos mais remotos até os dias atuais, os seres humanos se organizam em comunidades, garantindo a sobrevivência e a defesa de elementos essenciais para a sociedade. Entre os ideais almejados está a educação, que é um direito social e uma importante ferramenta de desenvolvimento e crescimento humano. Inclusive, a Constituição Federal em vigor consagra a cooperação entre o Poder Público e a coletividade como forma de efetivar o direito educacional.

Assim, a educação não é um dever exclusivo do Estado e da família, devendo ser promovida e incentivada pela sociedade. Como consequência, o

1 Graduanda em Direito pela Universidade do Vale do Taquari - Univates. E-mail: azbattisti@ universo.univates.br.

2 Mestre em Direito, pela Universidade de Santa Cruz do Sul - Unisc. Professora na Universidade do Vale do Taquari - Univates. E-mail: leila@univates.br. 
sistema reforça o caráter democrático do processo educacional, já que permite a mobilização de diversos setores da sociedade interessados em contribuir para a educação. Além disso, a cooperação possibilita um serviço mais eficiente e menos oneroso para o Estado.

Partindo desses três segmentos (educação, comunidade e democracia), o artigo percorrerá as linhas jurídicos-contratuais celebradas entre uma universidade comunitária (Universidade do Vale do Taquari - Univates) e o Poder Público (Município de Lajeado/RS), envolvendo a prestação de serviço em uma Escola Municipal de Educação Infantil. Assim, objetiva-se averiguar a incidência dos princípios constitucionais do direito à educação, notadamente o da gestão democrática, no contrato mencionado.

Tem-se como hipótese a aproximação da comunidade da administração da escola, de modo que o contrato representa uma manifestação do caráter democrático e dos princípios constitucionais voltados à educação. Assim, tornase efetivo o direito à educação e fortalece-se o viés comunitário da universidade, que concretiza a sua missão social, a partir de seu ramo extensionista.

O estudo será de natureza aplicada, de abordagem qualitativa e, quanto ao objetivo, exploratório. Para testar a sua verificabilidade, será utilizado o método dedutivo. Para a coleta de dados, serão utilizadas três técnicas instrumentais: bibliográfica, documental e estudo de caso.

Além da introdução e da conclusão, o trabalho está dividido em três partes. Por primeiro, abordar-se-á o direito social educacional e como este se constituiu no sistema jurídico brasileiro, analisando-se o histórico de todas as Constituições Federais e enfatizando-se os princípios. Na sequência, verificarse-á as formas pelas quais o sistema jurídico brasileiro garante a colaboração da sociedade no processo educacional, destacando-se as instituições comunitárias e o princípio da gestão democrática. Por fim, serão discutidas as características do contrato de prestação de serviço celebrado entre o Município de Lajeado/ RS e a Univates.

\section{Educação: um instrumento de transformação da sociedade}

Apesar de duas ciências distintas, o direito e a educação se complementam e constituem a base de toda a sociedade. Tanto é assim que a educação é reconhecida como um direito fundamental, previsto no artigo 26 da Declaração Universal dos Direitos Humanos, de modo que está presente nos ordenamentos jurídicos de todos os países (BITTAR, 2014). No Brasil, o direito à educação esteve previsto em todas as Constituições, tendo acompanhado os avanços e retrocessos da democracia brasileira.

No período colonial, a educação não era motivo de preocupação, tendo em vista que o Brasil era considerado mera fonte de riqueza (FLACH, 2009). Em 1824, com o advento do Império, foi promulgada a primeira Constituição nacional, a qual consagrou a instrução pública, mas excluiu os escravos (CURY 
e FERREIRA, 2010). A Constituição Republicana de 1891 apesar de não ter ignorado o direito à educação, refletiu o "liberalismo excludente e pouco democrático" da época (CURY, 2005, p. 80). Inclusive, o índice de analfabetismo chegou a 74,59\% em 1900 (FLACH, 2009).

De acordo com Flach (2009, p. 505), a Constituição de 1934 alterou positivamente o cenário educacional, pois previu a "necessidade de um plano nacional de educação, ensino gratuito e obrigatório", bem como "percentuais de receitas e impostos para a manutenção e desenvolvimento do ensino". Entretanto, a Constituição de 1937 retrocedeu quanto ao direito educacional, uma vez que restringiu os deveres do Estado e eliminou conquistas anteriores (FLACH, 2009). Nesse sentido, Cury e Ferreira (2010, p. 130) mencionam que o "texto constitucional aponta a responsabilidade dos pais quanto ao dever da educação, como primeiro dever e um direito natural, assumindo o Estado um papel supletivo e subsidiário".

Em 1945 inicia-se o processo de redemocratização do país, sendo que no ano seguinte uma nova Constituição é promulgada, a qual, em termos educacionais, não se distanciou da Carta de 1934 (CURY e FERREIRA, 2010). Flach $(2009$, p. 506) destaca que dos princípios educacionais assegurados pela Constituição de 1946 "a obrigatoriedade e a gratuidade do ensino primário figuram como grandes avanços", pois garantiram à parcela mais pobre da sociedade o acesso à escola.

Durante o período militar, a educação brasileira não sofreu mudanças expressivas, o que, na visão de Flach (2009, p. 507) "demonstra a desconsideração do novo regime pela instrução e formação intelectual da população". Apesar disso, Cury e Ferreira (2010) destacam que a Constituição de 1967 relacionou, pela primeira vez, a obrigatoriedade do ensino com a idade do aluno e não com a série ou ensino obrigatório.

Finalmente, a Constituição de 1988 "representou um avanço significativo em matéria educacional", notadamente porque ganhou status de direito social, ocupando o primeiro lugar no rol do artigo $6^{\circ}$. Além disso, o direito à educação foi detalhado no artigo 205 em diante da Constituição Federal, o que foi definido por Bulos (2018, p. 1611) como um "programa constitucional a ser seguido". O artigo inaugural desse complexo de normas "traz os elementos básicos daquilo que o constituinte entendeu por educação" (MALISKA, 2018, p. 2043).

Nesse sentido, o dispositivo prevê que a educação é direito de todos e dever do Estado e da família, devendo ser promovida e incentivada com a colaboração da sociedade. Como objetivos do direito educacional, o artigo 205 da Constituição Federal cita o desenvolvimento da pessoa, o preparo para o exercício da cidadania e a qualificação para o trabalho.

Maliska (2018) explica que a educação foi consagrada como direito de todos por ser indispensável na formação do indivíduo. O dever da família decorre da atribuição constitucional de educar os filhos, prevista nos artigos 
$208, \S 3^{\circ}, 227$ e 229 , que em resumo dispõem sobre o zelo pela frequência à escola e o direito da criança à educação.

Por conseguinte, o Estado deve oferecer escola para todos, isto é, a educação básica obrigatória e gratuita, compreendida dos 04 aos 17 anos de idade e para todos aqueles que não tiveram acesso em idade própria (artigo 208, inciso I, da Constituição Federal). Inobstante, o dever não é limitado ao ensino obrigatório, tendo em vista que que a legislação outorgou outras responsabilidades ao Estado, como, por exemplo, o fornecimento de creches (artigo 206, inciso IV, da Constituição Federal) (CURY e FERREIRA, 2010).

Finalmente, a colaboração da sociedade deve ser entendida a partir de duas perspectivas. De acordo com Maliska (2018), a primeira está vinculada à oferta do ensino privado e a segunda às oportunidades oferecidas na sociedade.

Quanto aos objetivos da educação, Piaget (1974, p. 61) destaca que o pleno desenvolvimento da pessoa humana compreende a necessidade de "formar indivíduos capazes de autonomia intelectual e moral e respeitadores dessa autonomia em outrem". O preparo para o exercício da cidadania consolida-se na capacidade de compreensão dos problemas políticos, sociais, econômicos, ambientais e culturais da comunidade ou do país (BITTAR, 2014). Por fim, a qualificação para o trabalho ganha especial relevância nos dias atuais, diante da competitividade do mercado e da exigência de preparo intelectual dos trabalhadores. Quanto ao ponto, Maliska (2018) reforça que a educação é mecanismo de aperfeiçoamento em uma sociedade marcada pela dinamicidade e inovação, que impõe, a cada dia, novos desafios aos trabalhadores.

Ainda, Lima, Soratto e Queiroz (2012) destacam o caráter democrático instituído ao processo educacional. Os autores ressaltam a preocupação do legislador em estabelecer instrumentos de efetividade para a garantia do direito à educação. Nesse sentido, Scaff e Pinto (2016) revelam que na Magna Carta há cerca de trinta disposições referentes ao direito educacional.

Entre tais mecanismos, destaca-se o artigo 206, que estabelece que o ensino deve ser ministrado com a observância dos princípios elencados em seus incisos. Tais preceitos tratam dos "direitos à igualdade, à liberdade, ao pluralismo, à gratuidade do ensino público, à gestão democrática, à qualidade do ensino e à valorização dos profissionais da educação" (MALISKA, 2018, p. 2045).

O primeiro princípio previsto no artigo 206 da Constituição Federal é o da igualdade de condições para o acesso e permanência na escola. Flach (2009) atenta que o legislador previu a igualdade de condições e não de oportunidades, o que, para ela, evidencia a intenção de assegurar a educação para todos. Já Maliska (2018) defende que o preceito deve ser utilizado como instrumento de correção das desigualdades fáticas, ou seja, a igualdade prevista em lei deve ser regulada de forma diferenciada. 
Prosseguindo, o princípio previsto no inciso II do artigo 206 da Constituição Federal assegura a liberdade de aprender, ensinar, pesquisar e divulgar o pensamento, a arte e o saber. Para Bulos (2018, p. 1613), o preceito garante a liberdade de cátedra, traduzindo-a como "direito subjetivo do professor ensinar aos seus alunos, sem qualquer ingerência administrativa, ressalvada, contudo, a possibilidade de fixação do currículo pelo órgão competente".

Vinculado ao referido princípio, tem-se o previsto no inciso III do artigo 206 da Constituição Federal, que trata do pluralismo de ideias e de concepções pedagógicas, bem como da coexistência de instituições públicas e privadas de ensino. Para Bulos (2018, p. 1613), o mencionado princípio objetiva eliminar: "(i) a centralização versus a descentralização; (ii) a qualidade das instituições versus a proliferação das academias de ensino; (iii) a terminalidade versus a continuidade da formação universitária".

Outro importante princípio constitucional é o da gratuidade do ensino público em estabelecimentos oficiais. Em virtude dessa previsão, o ensino público no Brasil é plenamente gratuito, ao contrário do que se observa em outros países, como Portugal, que admite a progressividade da gratuidade (MALISKA, 2018). Sendo assim, o Estado deve ofertar a educação sem qualquer ônus ao estudante, podendo voluntariamente haver alguma contribuição da família ou sociedade (FLACH, 2009).

Avançando, o inciso V do artigo 206 da Magna Carta garante a valorização dos profissionais da educação escolar. Para assegurar tal prestígio, a Constituição estabelece uma série de direitos aos professores, dentre os quais Maliska (2018, p. 2047) menciona "o ingresso no serviço público por concurso público, o aperfeiçoamento profissional continuado, com licenciamento periódico remunerado para esse fim e piso salarial profissional".

Outro princípio educacional consagrado na Constituição Federal é o da gestão democrática do ensino público. Para Maliska (2018), o princípio visa a garantir a participação da sociedade na educação. Bulos (2018, p. 1614), por sua vez, destaca que a consequência do preceito é a "escolha dos representantes das escolas, faculdades, institutos, diretorias, chefias e reitorias, mediante eleições livres".

Por fim, a Constituição Federal preceitua a garantia de padrão de qualidade do ensino. De acordo com Maliska (2018), o princípio compreende tanto o dever da escola em prestar um ensino de qualidade quanto o dever do Estado em promover a fiscalização. $\mathrm{O}$ autor ainda menciona que as duas situações geram direitos ao aluno, podendo exigir, por exemplo, professores capacitados e qualificados, além de bibliotecas e laboratórios equipados.

O percorrido até então permitiu demonstrar a importância da união entre o direito e a educação, o conturbado histórico do direito educacional e o sistema legislativo atualmente em vigor, que prevê uma série de princípios. 
Também foi visto que o dever de zelar pela educação é atribuído ao Estado e à família, o que, entretanto, não exime a sociedade.

\section{Direito de todos: a educação como um espaço democrático}

A participação da sociedade no processo educacional homenageia o caráter democrático da educação, recepcionado pela Constituição Federal. Tal perspectiva pode ser abordada a partir de dois segmentos. O primeiro, de caráter amplo, decorre da possibilidade da sociedade exercer serviços públicos e do surgimento de instituições voltadas à prestação desses serviços. Já o segundo, de cunho interno, concentra-se na análise da gestão das escolas.

Inicialmente, destaca-se que até o século XIX, em diversos países, imperava ordens de Estado Liberal, marcada por uma exponente desigualdade social. Após a Segunda Guerra Mundial, consolida-se o Estado Social, que também recebe o nome de "Estado do Bem-Estar, Estado Providência, Estado do Desenvolvimento, Estado Social de Direito" (DI PIETRO, 2019, p. 08).

A partir de então atribui-se ao Estado a missão de alcançar a igualdade social, sendo necessária a sua intervenção na ordem econômica e social (DI PIETRO, 2019). Para que o Estado atingisse seu objetivo, ampliou-se o rol de suas atribuições. Assim, a saúde, a educação e a assistência social, que antes não eram preocupações do Estado, passaram a ser seu dever (SCHMIDT, 2017).

Entretanto, o crescimento do Estado implicou em diversas consequências negativas e certo "descontrole" da administração pública. Nesse sentido, Di Pietro (2019) menciona a exagerada burocratização e a estrita aplicação do princípio da legalidade, sendo que a lei "passou a ser vista em seu aspecto estritamente formal, despida de qualquer conteúdo de justiça" (DI PIETRO, 2019, p. 12).

Todo esse cenário exigiu transformações no papel do Estado, sendo que a solução encontrada foi a de possibilitar a participação ativa dos cidadãos na gestão pública (CERVI, 2013). Para Di Pietro (2019), a nova mudança estrutural da Administração marca a introdução de um novo elemento: a ideia de Estado Democrático.

Com isso, consagra-se o princípio da subsidiariedade, que, de acordo com Cervi (2013, p. 101), conduz ao entendimento de que o Estado "não deve ser a única ou, ao menos, a primeira fonte de serviços sociais". Etzioni (2019, p. 64) complementa referindo que "nenhuma tarefa social deve ser atribuída a uma instituição que seja maior do que o necessário para realizar o trabalho.

Como consequência desse princípio, Di Pietro (2019) destaca que a proteção ao interesse público deixa de ser prerrogativa exclusiva do Estado, eis que não possui condições de assumir todas as reivindicações da sociedade pluralista. Assim, o Estado se responsabiliza pelas atividades consideradas indelegáveis (segurança, justiça, legislação e relações exteriores) e exerce em caráter supletivo às sociais e econômicas (DI PIETRO, 2019). 
Nesse cenário, Schmidt (2017, p. 66) ressalta a popularização de novos conceitos, como, por exemplo, "terceira via, terceiro setor, instituições híbridas, esfera pública não estatal, comunidade cívica, comunidades de políticas, governança, justiça comunitária e mediação comunitária". Oliveira (2019, p. 221) explica que o Terceiro Setor compreende as "entidades da sociedade civil sem fins lucrativos, que desempenham atividades de interesse social mediante vínculo formal de parceria com o Estado". Ou seja, o Terceiro Setor localiza-se entre o Estado e o mercado.

Apesar de muitos autores, não concordarem com a classificação, as instituições comunitárias pertencem ao Terceiro Setor e se destacam na prestação de serviços educacionais. Entre essas, têm-se as universidades comunitárias regionais, fundadas no Sul do país.

De acordo com Schmidt (2017, p. 47), essas instituições "são criadas por organizações da sociedade civil e do poder público local/regional". Além disso, possuem uma mantenedora, que pode se constituir por meio de associações ou fundações, bem como são dotadas de autonomia e capacidade de autogestão (SCHMIDT, 2017).

Schmidt (2017) menciona que as universidades comunitárias se preocupam com as necessidades do contexto social e se caracterizam pela inserção na comunidade. $\mathrm{O}$ autor também ressalta que são marcadas pela participação dos diversos segmentos no processo decisório e pela transparência sobre informações acadêmicas e situação financeira.

Ademais, a gestão dessas instituições possui caráter público, o que explica a imprescindibilidade do tratamento igualitário a todos os cidadãos e a admissão de docentes através de processo seletivo (SCHMIDT, 2017). Finalmente, a última característica mencionada pelo autor é a eficácia e a eficiência. Ou seja, as universidades comunitárias devem procurar cumprir seus objetivos institucionais de forma satisfatória e oferecer educação de qualidade com os custos compatíveis.

Conquanto, apesar da importância e da presença de diversas instituições comunitárias educacionais no sul do Brasil, destaca-se que até há pouco tempo não possuíam uma legislação adequada. Por isso, no ano de 2004, defensores dessas instituições iniciaram diversas reivindicações, até que, no ano de 2013, foi promulgada a Lei 12.881, que dispõe sobre a definição, qualificação, prerrogativas e finalidades das Instituições Comunitárias de Educação Superior - ICES (SCHMIDT, 2017).

Uma lei que inaugura uma nova era para as universidades comunitárias, que abre as portas para um processo amplo de cooperação entre o poder público e as organizações criadas pelas comunidades com o fito de proporcionar educação superior de qualidade a todos (SCHMIDT, 2017, p. 59). 
Destaca-se ainda que, na sua redação original, a Lei de Diretrizes e Bases da Educação Nacional adotou apenas duas modalidades de instituições de ensino: pública e privada. As instituições comunitárias foram arroladas dentro das privadas, não havendo distinção entre ambas (SCHMIDT, 2017).

Diante de tal omissão, no dia 12 de dezembro de 2017, foi apresentado o Projeto de Lei 9.308, que teve por objetivo alterar a Lei de Diretrizes e Bases da Educação Nacional para incluir as universidades comunitárias no rol de instituições de ensino e torná-las aptas a participar do Conselho Nacional de Educação - CNE. Entre os argumentos utilizados na justificação, citase a confusão gerada pela ausência de reconhecimento das universidades comunitárias e ressalta-se a importância dessas instituições para a educação brasileira (BRASIL, Projeto Lei 9.308, texto digital, 2020).

Em 2019, após regular tramitação, o Projeto foi sancionado, passando a integrar a Lei 13.868, que altera as Leis 4.024, de 20 de dezembro de 1961, e 9.394, de 20 de dezembro de 1996, para incluir disposições relativas às universidades comunitárias. A partir de então, as universidades comunitárias constituem o sistema federal de ensino, estando devidamente previstas no inciso III do artigo 19 da Lei de Diretrizes e Bases da Educação Nacional.

Prosseguindo, o segundo segmento que garante a democracia participativa da educação é as relações internas dos educandários. Isso, porque a administração hegemônica das escolas, marcada pela figura do diretor, transformou-se. Hoje em dia são os professores, equipe pedagógica, funcionários, alunos, pais e comunidade que constroem o ambiente escolar (LÜCK, 2000).

Quanto ao ponto, Schneckenberg (2000) menciona que a gestão democrática contribui para a qualidade de aprendizagem, pois exige que os dirigentes conheçam a realidade, as condições e os desafios enfrentados pelos alunos. Assim, os grupos sociais devem unir esforços para a efetivação desses objetivos.

É importante e necessário que a gestão escolar promova um clima propício à participação das pessoas, dos professores, dos alunos, dos pais e dos demais membros da comunidade, no processo de implementação de uma reforma educacional. Cabe considerar a experiência de cada membro da comunidade escolar, seus conhecimentos específicos, suas necessidades e anseios no que se refere ao desenvolvimento da instituição escolar e dos seus próprios interesses, é um espaço onde cada um sente que faz parte (SCHNECKENBERG, 2000, p. 119).

Além disso, Lück (2000) destaca que a gestão democrática educacional contribui para que a escola seja um instrumento de formação da cidadania. A autora explica que "desse trabalho compartilhado, orientado por uma 
vontade coletiva, cria-se um processo de construção de uma escola competente compromissada com a sociedade" (LÜCK, 2000, p. 27).

Ainda, Queiroz e Oliveira (2018) destacam que o princípio da gestão democrática reforça o sentimento de democracia social, pois preserva as realidades de cada região, principalmente em virtude da participação da comunidade escolar no planejamento do projeto pedagógico. No mesmo sentido, Souza (2012, texto digital) leciona que tal colaboração permite que a comunidade se sinta parte integrante do processo de transformação da realidade escolar, de modo a alcançar "uma sociedade mais justa, igualitária e cidadã".

Destaca-se que são utilizados diversos mecanismos para garantir a democracia participativa escolar, como, por exemplo, a criação de órgãos colegiados. Parente e Lück (2000) indicam e conceituam alguns desses órgãos, iniciando pelo Conselho Escolar, que tem como objetivo "promover a participação da comunidade escolar nos processos de administração e gestão da escola, visando assegurar a qualidade do trabalho escolar em termos administrativos, financeiros e pedagógicos" (PARENTE e LÜCK, 2000, p. 157). De acordo com as escritoras, para efetivar os objetivos, o Conselho Escolar desempenha funções normativas, deliberativas e fiscalizadoras.

Parente e Lück (2000) também mencionam a Associação de Pais e Mestres - APM, que, como o próprio nome indica, é formada por pais de alunos, professores e funcionários. As autoras mencionam que a finalidade da Associação é "auxiliar a direção escolar na promoção das atividades administrativas, pedagógicas e sociais da escola, bem como arrecadar recursos para complementar os gastos com o ensino, a educação e a cultura" (PARENTE e LÜCK, 2000, p. 158).

A Caixa Escolar, também mencionada pelas autoras, "é uma instituição jurídica, de direito privado, sem fins lucrativos, que tem como função básica administrar os recursos financeiros da escola, oriundos da União, Estados e municípios, e aqueles arrecadados pelas unidades escolares" (PARENTE e LÜCK 2000, p. 159). Por fim, nas palavras de Parente e Lück (2000, p. 159), o Colegiado Escolar "é um órgão coletivo, consultivo e fiscalizador".

Destaca-se que todos os órgãos colegiados mencionados são interdependentes, sendo que suas funções, competências e objetivos se complementam. Ainda, todas as estruturas apresentam uma característica em comum, que é a participação de diversos atores na gestão escolar (PARENTE e LÜCK, 2000). Por isso, Souza (2012, texto digital) entende que os órgãos colegiados constituem "ferramenta imprescindível à gestão democrática".

Por todo o exposto destaca-se que, além de ser resultado de um processo histórico-social, a gestão democrática compreende um princípio constitucional. Tal preceito possui duas perspectivas: a prestação de serviço educacional e a 
participação da comunidade escolar no processo pedagógico, administrativo e financeiro da escola.

Por fim, salienta-se que, apesar do caráter democrático educacional ter evoluído ao longo do tempo, outros mecanismos podem e devem ser criados para possibilitar a aproximação comunitária da escola. Um desses métodos foi utilizado pelo Município de Lajeado/RS, que inovou ao celebrar um contrato de prestação de serviços com a Universidade do Vale do Taquari - Univates, o qual será explorado no próximo tópico.

\section{Instrumento democrático: o contrato de prestação de serviço celebrado entre} o Município de Lajeado/RS e a Universidade do Vale do Taquari - Univates

O contrato de prestação de serviço está disciplinado nos artigos 593 a 609 do Código Civil. Para Tartuce (2020, p. 562), essa espécie contratual compreende um "negócio jurídico pelo qual alguém - o prestador - compromete-se a realizar uma determinada atividade com conteúdo lícito, no interesse de outrem - o tomador -, mediante certa e determinada remuneração".

Além de ser muito explorado pelo direito privado, o contrato de prestação de serviço também é utilizado no âmbito da Administração Pública. É através desse instrumento que o Estado descentraliza a execução de alguns serviços, destinando-os a terceiros, como forma de atender todas as suas atribuições. Destaca-se que, quando celebrado nesse âmbito, o contrato de prestação de serviços observará as diretrizes de direito público.

Por isso, o contrato deverá ser destinado a prestação de serviço público. Para Di Pietro (2019, p. 136), serviço público compreende "toda atividade material que a lei atribui ao Estado para que a exerça diretamente ou por meio de seus delegados, com o objetivo de satisfazer concretamente às necessidades coletivas, sob regime jurídico total ou parcialmente público". A autora ainda acrescenta que os serviços públicos devem respeitar três princípios, denominados de continuidade do serviço público, mutabilidade do regime jurídico e igualdade de usuários.

Além disso, o contrato administrativo deve ter finalidade pública, ou seja, a Administração só está autorizada a formalizar um negócio jurídico objetivando o interesse da coletividade (DI PIETRO, 2019). Também é por isso que a Administração ocupa uma posição de supremacia sobre o particular, que se manifesta através das chamadas cláusulas exorbitantes (DI PIETRO, 2019).

As mencionadas cláusulas conferem prerrogativas à Administração em detrimento do particular, independentemente de estarem previstas no contrato (OLIVEIRA, 2020). Estas cláusulas estão arroladas nos incisos do artigo 58 da Lei 8.666/1993 e são mencionadas por Gasparini (2012, p. 807): “a) modificar a execução do contrato a cargo do contratante particular; b) acompanhar a execução do contrato; c) impor sanções previamente estipuladas; d) rescindir, por mérito ou legalidade, o contrato". Aliado a isso, destaca-se 
que o instrumento firmado pela Administração compreende um contrato de adesão, ou seja, "todas as cláusulas dos contratos administrativos são fixadas unilateralmente pela Administração" (DI PIETRO, 2019, p. 307).

Inobstante, o contrato administrativo deve obedecer as formalidades legais, que, em caráter geral, estão arroladas na Lei 8.666/1993 (DI PIETRO, 2019). Como exemplo, pode-se citar a vedação de contratos verbais, a imposição de prazo determinado e a exigência de prévia licitação (OLIVEIRA, 2020).

Além de respeitar determinadas formalidades, Di Pietro (2019) sustenta que o contrato administrativo deve observar o procedimento legal. Nesse sentido:

A lei estabelece determinados procedimentos obrigatórios para a celebração de contratos e que podem variar de uma modalidade para outra, compreendendo medidas como autorização legislativa, avaliação, motivação, autorização pela autoridade competente, indicação de recursos orçamentários e licitação (DI PIETRO, 2019, p. 306).

Apesar do contrato administrativo ser, em regra, precedido de licitação, a Lei 8.666/1993 prevê causas de dispensa e inexigibilidade. Dentre as causas de dispensas, que estão taxativamente arroladas no artigo 24, destaca-se a prevista no inciso XIII do dispositivo ${ }^{3}$. Oliveira (2020, p. 72) traduz a hipótese da seguinte forma:

É possível a dispensa de licitação para contratar instituição brasileira, sem fins lucrativos e de inquestionável reputação ético-profissional, que tenha por objetivo desenvolver, por força estatutária, uma das seguintes atividades: pesquisa, ensino, desenvolvimento institucional ou recuperação social do preso.

Por fim, Di Pietro (2019) defende que o contrato administrativo é dinâmico, denominando tal característica de "mutabilidade". Nessa perspectiva, Oliveira (2020, p. 238) explica que:

A mutabilidade natural do interesse público, em razão da alteração da realidade social, política e econômica, acarreta a maleabilidade (instabilidade) nos contratos administrativos. Enquanto nos contratos privados sempre vigorou a ideia, hoje muito mitigada

3 Art. 24. É dispensável a licitação: [...] XIII - na contratação de instituição brasileira incumbida regimental ou estatutariamente da pesquisa, do ensino ou do desenvolvimento institucional, ou de instituição dedicada à recuperação social do preso, desde que a contratada detenha inquestionável reputação ético-profissional e não tenha fins lucrativos [...] (BRASIL, Lei 8.666/1993, texto digital, 2020). 
pelas teorias revisionistas, do pacta sunt servanda, nos contratos administrativos a instabilidade é uma nota essencial.

Expostas as características do contrato de prestação de serviço, necessário analisar os sujeitos da relação jurídica objeto do presente estudo. Para tanto, esclarece-se que na esfera contratante situa-se o Município de Lajeado/RS e na esfera contratada a Universidade do Vale do Taquari - Univates.

O Município de Lajeado/RS se localiza no "coração" do Estado do Rio Grande do Sul e integra a região do Vale do Taquari, que foi colonizada por Açorianos, no Século XVI. Posteriormente, em meados de 1850, os primeiros imigrantes alemães se instalaram na região e, na sequência, os italianos. Destaca-se que a ausência do Poder Público e as ideologias cidadãs trazidas pelos colonizadores fizeram com que a população se desenvolvesse com os próprios meios de subsistência. Sendo assim, o associativismo fortaleceu-se na região, podendo-se verificar uma manifestação de organização comunitária (BERSCH, 2009).

Deve-se esclarecer que os Municípios possuem o dever constitucional de zelar pela educação fundamental e infantil. Nesse sentido, o artigo 208 da Magna Carta assegura que o Estado deverá garantir a educação básica dos 4 aos 17 anos, bem como para todos que não tiveram acesso ao ensino na idade própria. Já o inciso IV, do mesmo dispositivo, dispõe especificamente sobre a garantia da educação infantil, que deve ser ofertada em creches ou pré-escolas às crianças de até 5 anos.

Não obstante, o artigo 211 da Constituição Federal assegura o regime de colaboração entre a União, os Estados, o Distrito Federal e os Municípios, atribuindo a estes a atuação prioritária no ensino fundamental e na educação infantil. Tal previsão, entretanto, impõe um grande desafio aos Municípios, tendo em vista que é expressivo o número de crianças na faixa etária de 0 a 5 anos, mas precária a estrutura e o orçamento Municipal.

Por isso, Cervi (2013, p. 127) exalta a importância das políticas públicas implementadas pelos Municípios e os "instrumentos de governança cooperativa". Para ele, "a participação social, além de conceder maior legitimidade às decisões governamentais, também tem a função de qualificar a atuação da administração pública" (CERVI, 2013, p. 126). E complementa:

As políticas públicas, como forma de empoderamento social local, devem ser pensadas sob a perspectiva do princípio da subsidiariedade, mais especificamente na sua dimensão horizontal. Isso implica em permitir não apenas que os municípios desenvolvam suas capacidades para desempenhar sua autonomia constitucional em nome do interesse local, mas também em o Estado assumir seu papel de indutor de tais políticas e permitir que a sociedade civil organizada atua para concretizar os direitos 
sociais, dentro das suas possibilidades, como forma de gestão participativa (CERVI, 2013, p. 126).

No mais, a Lei $9.291 / 2013^{4}$ regulamenta a gestão democrática das Escolas Municipais de Lajeado. A legislação confere aos educandários autonomia administrativa, financeira e pedagógica. Para isso assegurar, a lei elenca diversas medidas que devem ser respeitas. Como exemplo, destaca-se a nomeação do Diretor e Vice-Diretor por votação direta da comunidade escolar.

Outrossim, a legislação confere especial importância ao Conselho Escolar, atribuindo a ele funções consultivas, deliberativas, fiscalizadoras, propositivas e mobilizadoras naquilo que se refere a gestão pedagógica, administrativa e financeira. Além do Conselho Escolar, a legislação prevê outros dois órgãos auxiliares na gestão das escolas. Nesse sentido, o artigo 58 dispõe sobre as Associação de Pais e Funcionários - APFs e os Círculos de Pais e Mestres - CPMs.

Do outro lado da relação contratual está a Univates, que se localiza no Município de Lajeado/RS e possui origem no envolvimento comunitarista enraizado na história da cidade. Nesse sentido, Bersch (2009, p. 276) menciona que "o surgimento da Univates segue a mesma lógica que comandou o surgimento das escolinhas de alfabetização nas áreas rurais de imigração alemã e italiana no sul do Brasil".

Destaca-se que a Univates foi qualificada como Instituição Comunitária de Educação Superior - ICES, por meio da Portaria do Ministério da Educação - MEC no 667, de 05 novembro de 2014 ${ }^{5}$. De acordo com o Estatuto constante no site $^{6}$ da universidade, a Univates possui como princípios a "pluralidade, natureza comunitária, responsabilidade social, sustentabilidade financeira, excelência acadêmica e transparência".

Cumpre destacar também que a sua missão institucional consiste em

gerar, mediar e difundir o conhecimento técnico-científico e humanístico, considerando as especificidades e as necessidades da realidade regional, inseridas no contexto universal, com vistas à expansão contínua e equilibrada da qualidade de vida (UNIVATES, texto digital).

4 https://leismunicipais.com.br/a2/rs/1/lajeado/lei-ordinaria/2013/930/9291/leiordinaria-n-9291-2013-disciplina-a-gestao-democratica-nas-escolas-publicas-municipais-delajeado?q=LEI+N\%C2\%BA+9291

5 https://pesquisa.in.gov.br/imprensa/jsp/visualiza/index.jsp?data=06/11/2014\&jornal $=1 \&$ pagina $=19 \&$ total Arquivos $=136$

6 https://www.univates.br/institucional/missao-visao-principios 
Para concretizar a sua missão, a Univates institui diversas ações, por meio de seu ramo extensionista, que objetivam a aproximação entre a comunidade local e a comunidade acadêmica, sendo meio de transformação dos agentes participantes. Nesse sentido, Rezende (2019) refere que os programas de extensão compreendem uma forma de a universidade "abrir as portas", tanto para mostrar aquilo que produz como para aprender com os diversos setores sociais. Em complementação, Santos (2010, p. 73) ressalta que os programas de extensão possibilitam às universidades "participação ativa na construção da coesão social, no aprofundamento da democracia, na luta contra a exclusão social e a degradação ambiental, na defesa da diversidade cultural".

Aliando o dever constitucional do Município e as diretrizes da Univates, os sujeitos acima caracterizados firmaram um contrato, cujo objetivo é estabelecer parceria visando a prestação de serviços educacionais e de formação pedagógica na Escola de Educação Infantil localizada no Bairro Santo Antônio, no Município de Lajeado/RS. Nesse âmbito, a finalidade estabelecida foi a oferta de vagas para atendimento de crianças entre quatro meses e cinco anos, em turno integral e/ou parcial.

Entre as obrigações atribuídas à Univates, tem-se a inserção de estudantes da universidade na escola, bem como o desenvolvimento de projetos e ações, por meio das atividades de ensino, pesquisa e extensão, que objetivem a qualificação da proposta pedagógica. Além disso, a universidade se responsabilizou em promover programas de qualificação dos profissionais que prestam os serviços no educandário. Ainda, a Univates deve adotar políticas destinadas ao atendimento das crianças e de seus familiares, "com dignidade e respeito, de modo universal e igualitário, mantendo, sempre, a qualidade na prestação dos serviços" (segunda cláusula do contrato). Ressaltase ainda uma das responsabilidades da Univates prevista no contrato, que é a continuidade dos serviços, bem como o zelo pela qualidade e eficiência das ações educacionais, recreativas e de pesquisa (quarta cláusula do contrato).

Avançando, o Município de Lajeado/RS deve possibilitar "o desenvolvimento das atividades de ensino, pesquisa e extensão, propostas por professores e estudantes da Univates". Além disso, o Município deverá promover o pagamento pela prestação de serviço, bem como acompanhar e avaliar a execução do contrato (quinta cláusula do contrato).

Quanto ao quadro de pessoal da escola, a Univates está autorizada a contratar os profissionais para prestar os serviços, devendo observar os princípios da legalidade, impessoalidade, moralidade, publicidade e eficiência. Inobstante, a contratada deverá indicar um profissional para exercer a função de interlocutor com a direção da escola, o qual ainda ficará encarregado pela gestão da equipe (oitava cláusula do contrato).

No mais, dentre as incumbências do diretor está a coordenação, a execução e a avaliação do projeto administrativo-financeiro-pedagógico. Além disso, o dirigente deverá apresentar os resultados da avaliação institucional da 
escola ao Conselho Escolar, à comunidade escolar e à Secretaria Municipal de Educação, bem como necessitará expor as propostas que visem a melhoria da qualidade de ensino. Também cabe ao diretor informar a comunidade escolar sobre a movimentação financeira da escola, bem como as diretrizes e normas emanadas pelo Sistema Municipal de Ensino (nona cláusula do contrato).

Finalmente, dentre as obrigações do coordenador pedagógico, destacase a elaboração, execução e avaliação de projetos de formação continuada dos profissionais da educação. Da mesma forma, ressalta-se que cabe ao coordenador participar do processo de integração família-escola-comunidade (nona cláusula do contrato).

Diante de todo o exposto, destaca-se que o contrato de prestação de serviço é um mecanismo utilizado pela Administração Pública para descentralizar a execução de alguns serviços a terceiros, de forma a atender suas atribuições. $O$ contrato analisado foi firmado por uma universidade pertencente ao terceiro setor (em seu conceito amplo) e por um ente público, sendo que ambos possuem suas origens na lógica comunitária, pois cresceram e se desenvolveram num contexto de participação popular.

Os sujeitos aliaram o dever constitucional do Município e o preceito comunitarista da universidade, de forma a garantir um serviço público eficaz. Por isso, o contrato traduz a preocupação em garantir a participação da comunidade escolar e acadêmica na administração do educandário. Assim, é certo que o contrato homenageia o princípio constitucional da gestão democrática, previsto no inciso VI do artigo 206 da Constituição Federal, bem como com as determinações previstas na Lei da Gestão Democrática do Município de Lajeado/RS.

Para além do caráter democrático, é perceptível a incidência de outros preceitos constitucionais educacionais no contrato, como a valorização do profissional da educação, a garantia pelo padrão de qualidade do ensino e a igualdade de condições para o acesso e permanência na escola, bem como é visível a aplicação dos princípios administrativos.

\section{Conclusão}

Como visto, a educação, a comunidade e a democracia são elementos essenciais para a vida em sociedade. Por esse motivo, a coletividade deve participar ativamente da garantia ao ensino, que é um serviço público. Nessa perspectiva, a colaboração entre a Administração e a coletividade, na busca por uma educação eficiente, possibilita o fortalecimento da cidadania e a preparação dos indivíduos para a vida pessoal e profissional, contribuindo para o avanço da sociedade.

Apesar disso, constatou-se que a educação nem sempre foi tema de destaque nas Constituições Federais brasileiras, tendo acompanhado os avanços e retrocessos da democracia no país. Nesse sentido, verificou-se que 
a atual Constituição Federal atribui à educação o status de fundamental e consagra mecanismos que auxiliam na garantia desse direito, como a previsão de diversos princípios constitucionais. Outro mecanismo previsto no sistema legislativo brasileiro é a participação da sociedade na prestação de serviços públicos.

Nessa perspectiva, a pesquisa revelou que a atuação das instituições comunitárias na educação possibilita a efetivação do ensino e um serviço menos oneroso para a Administração Pública. Também verificou-se que a participação da sociedade no processo de ensino evidencia o caráter democrático atribuído à educação, fazendo valer o princípio constitucional da gestão democrática. Tal preceito, conforme visto, garante a participação conjunta de pais, alunos, professores, funcionários e direção na gestão administrativa-pedagógicafinanceira da escola.

A partir disso, pode-se afirmar que o contrato de prestação de serviço celebrado entre o Município de Lajeado/RS e a Univates torna efetivo o direito educacional e eficaz o dever da Administração. Efetivo, porque o contrato respeita os princípios constitucionais estabelecidos e garante o acesso à escola de educação infantil. Eficaz, pois torna possível o serviço público, de forma a criar e ofertar vagas às crianças de até 5 anos.

Além disso, verificou-se que as cláusulas contratuais asseguram os preceitos constitucionais educacionais, possibilitando a participação ativa da comunidade local e escolar na gestão da escola. No mesmo sentido, o contrato reforça o caráter comunitário da universidade, pois viabiliza a prática daquilo que é estudado na academia e permite o aprendizado com o ambiente local.

Outrossim, constatou-se que o contrato incentiva a participação da sociedade na busca pela garantia da educação, fortalecendo a formação da cidadania. Dessa forma, ao passo que a sociedade se preocupa com a educação, se inserindo na gestão da escola, os educandários se comprometem com o futuro da comunidade. Assim, pode-se destacar que a colaboração social é necessária para a educação, pelo que não deve ser entendida como um dever próprio dos pais e do Estado.

Por tudo isso, pode-se concluir que as organizações públicas não estatais apresentam destaque na construção de uma democracia forte e inclusiva. Ao lado disso, pode-se concluir que o contrato, inovador na região, supera as expectativas e se mostra como uma forte tendência comunitária-administrativa.

\section{Referências}

ASSEMBLEIA GERAL DAS NAÇÕES UNIDAS. Declaração Universal dos Direitos Humanos. 1948. Disponível em: https://www.un.org/en/universal-declarationhuman-rights/. Acesso em: 24 ago. 2020. 
BERSCH, Roque Danilo. Centro Universitário Univates: um centro universitário comunitário. In: SCHMIDT, João Pedro (Org.). Instituições públicas não-estatais. Santa Cruz do Sul: EDUNISC, 2009. p. 275-282. E-book.

BITTAR, Carla Bianca. Educação e direitos humanos no Brasil. São Paulo: Saraiva, 2014.

BRASIL. Constituição (1988). Constituição da República Federativa do Brasil. Disponível em: http:/ /www.planalto.gov.br/ccivil_03/constituicao/constituicao. htm. Acesso em: 25 abr. 2020.

BRASIL. Lei 8.666, de 21 de junho de 1993. Regulamenta o art. 37, inciso XXI, da Constituição Federal, institui normas para licitações e contratos da Administração Pública e dá outras providências. Disponível em: http:/ / www.planalto.gov.br/ ccivil_03/leis/18666cons.htm. Acesso em: 21 out. 2020.

BRASIL. Lei 9.394, de 20 de dezembro de 1996. Lei de Diretrizes e Bases da Educação Nacional. Disponível em: http:/ / www.planalto.gov.br/ccivil_03/leis/19394.htm. Acesso em: 12 ago. 2020.

BRASIL. Lei 10.406, de 10 de janeiro de 2002. Código Civil. Disponível em: http:/ / www.planalto.gov.br/ccivil_03/leis/2002/L10406compilada.htm. Acesso em: 20 out. 2020.

BRASIL, Lei 12.881, de 12 de novembro de 2013. Dispõe sobre a definição, qualificação, prerrogativas e finalidades das Instituições Comunitárias de Educação Superior - ICES, disciplina o Termo de Parceria e dá outras providências. Disponível em: http:/ /www.planalto.gov.br/ccivil_03/_ato2011-2014/2013/lei/112881.htm. Acesso em: 12 set. 2020.

BRASIL, Projeto de Lei 9.308/2017. Altera a Lei 4.024 de 20 de dezembro de 1961 e a Lei 9.394 de 20 de dezembro de 1996. Disponível em: https:/ / www.camara.leg.br/ proposicoesWeb/prop_mostrarintegra?codteor=1643813\&filename=PL+9308/2017. Acesso em: 15 set. 2020.

BRASIL, Lei 13.868, de 3 de setembro de 2019. Altera as Leis 4.024, de 20 de dezembro de 1961, e 9.394, de 20 de dezembro de 1996, para incluir disposições relativas às universidades comunitárias. Disponível em: http:/ /www.planalto.gov.br/ccivil_03/_ Ato2019-2022/2019/Lei/L13868.htm. Acesso em: 15 set. 2020.

BULOS, Uadi Lammêgo. Curso de Direito Constitucional. 11 a ed. São Paulo: Saraiva Educação, 2018. E-book. Disponível em: www.univates.br/biblioteca. Acesso em: 26 abr. 2020.

CERVI, Jacson R. As contribuições do comunitarismo responsivo para as intersecções entre o público e o privado no estado democrático de direito. In: SCHMIDT, João Pedro; HELFER, Inácio; BORBA, Ana Paula de Almeida de. Comunidade e Comunitarismo: temas em debate. Curitiba: Multideia, 2013. p. 97-134 
CURY, Carlos Roberto Jamil. A educação na revisão constitucional de 1926. In: FÁVERO, Osmar (Org.). A Educação nas Constituintes Brasileiras: 1823-1988. $3^{\mathrm{a}}$ ed. São Paulo: Autores associados, 2005.

CURY, Carlos Roberto Jamil; FERREIRA, Luiz Antonio Miguel. Obrigatoriedade da educação das crianças e adolescentes: uma questão de oferta ou de efetivo atendimento? Nuances: estudos sobre educação. Presidente Prudente, São Paulo, v. 17, n. 18, p. 124-145. Disponível em: file:/ / /C:/Users/Usuario/Downloads/729-20191-PB\%20(1).pdf. Acesso em: 24 ago. 2020.

DI PIETRO, Maria Sylvia Zanella. Direito Administrativo. $32^{a}$ ed. Rio de Janeiro: Forense, 2019. E-book. Disponível em: www.univates.br/biblioteca. Acesso em: 10 out. 2020.

Parcerias na Administração Pública: concessão, permissão, franquia, terceirização, parceria público-privada. $12^{a}$ ed. Rio de Janeiro: Forense, 2019. E-book. Disponível em: www.univates.br/biblioteca. Acesso em: 12 set. 2020.

ETZIONI, Amitai. A terceira via para a boa sociedade. Tradução de João Pedro Schmidt. Santa Cruz do Sul: EDUNISC, 2019. E-book. Disponível em: https:/ / repositorio.unisc.br/jspui/bitstream/11624/2721/1/A\%20terceira\%20via\%20 para \%20a\%20boa\%20sociedade.pdf. Acesso em: 18 set. 2020.

FLACH, Simone de Fátima. O direito à educação e sua relação com a aplicação da escolaridade obrigatório no Brasil. Ensaio: Avaliação e Políticas Públicas em Educação. Rio de Janeiro, v. 17, n. 64, p. 495-520. Disponível em: https:/ /www.scielo. br/pdf/ensaio/v17n64/v17n64a06.pdf. Acesso em: 24 ago. 2020.

GASPARINI, Diogenes. Direito Administrativo. 17ª ed. São Paulo: Saraiva, 2012. E-book. Disponível em: www.univates.br/biblioteca. Acesso em: 08 out. 2020.

LAJEADO. Lei 9.291, de 03 de outubro de 2013. Disciplina a gestão democrática nas escolas públicas municipais de Lajeado. Disponível em: https:/ / leismunicipais. com.br/a2/rs/1/lajeado/lei-ordinaria/2013/930/9291/lei-ordinaria-n-92912013-disciplina-a-gestao-democratica-nas-escolas-publicas-municipais-delajeado?q=LEI+N\%C2\%BA+9291. Acesso em: 21 out. 2020.

LAJEADO. Contrato Administrativo n 031-04/2020. Dispõe sobre a contratação da Universidade do Vale do Taquari - Univates, para prestação de serviços educacionais e formação pedagógica em escola de Educação Infantil, localizada no Bairro Santo Antônio, no Município de Lajeado/RS. Assinado em: 03 mar. 2020. Disponível em: https:/ / www.lajeado.rs.gov.br/?titulo=Portal\%20da\%20Transpar\%EAncia\&template $=$ servico \&categoria $=972 \&$ codigoCategoria $=972 \&$ servico $=70452 \&$ idConteudo $=3532$. Acesso em: 07 nov. 2020.

LIMA, Aires David de; SORATTO, Fernanda Peres; QUEIROZ, Renato Barbosa. A Judicialização da Educação no Brasil: Garantias Constitucionais. Anais Sciencult, Parnaíba, Piauí, v. 4, n. 1, p. 5-14, 2012. Disponível em: https:/ / anaisonline.uems.br/ index.php/sciencult/article/view/3305. Acesso em: 20 mar. 2020. 
LÜCK, Heloísa. Perspectivas da gestão escolar e implicações quanto à formação de seus gestores. Revista Em Aberto, Brasília, v. 17, n. 72, p. 11-33, fev./jun. 2000. Disponível em: http:// portal.inep.gov.br/documents/186968/485895/Gest\%C3\% A3o+escolar+e+forma\%C3\%A7\%C3\%A3o+de+gestores/3d03dfb4-3a86-4b24-b17ff140ea58bd45? version=1.3. Acesso em: 13 set. 2020.

MALISKA, Marcos Augusto. Da educação. In: CANOTILHO, J. J. Gomes [et al]. Comentários à Constituição do Brasil. 2 ${ }^{\mathrm{a}}$ ed. São Paulo: Saraiva Educação, 2018.

MINISTÉRIO DA EDUCAÇÃO. Portaria 667, de 05 de novembro de 2014.

Qualifica como Instituição Comunitária de Educação Superior (ICES) o Centro Universitário UNIVATES, Código 1041, mantida pela Fundação Vale do Taquari de Educação e Desenvolvimento Social-FUVATES, CNPJ nº 04.008.342/000109. Disponível em: https:/ / pesquisa.in.gov.br/imprensa/jsp/visualiza/index. jsp?data=06/11/2014\&jornal=1\&pagina=19\&totalArquivos=136. Acesso em: 04 nov. 2020.

OLIVEIRA, Rafael Carvalho Rezende. Curso de Direito Administrativo. $7^{\mathrm{a}}$ ed. Rio de Janeiro: Forense, 2019. São Paulo: Método, 2019. E-book. Disponível em: www. univates.br/biblioteca. Acesso em: 30 abr. 2020.

Licitações e contratos administrativos: teoria e prática. $9^{\text {a }}$ ed. Rio de Janeiro: Forense; São Paulo: Método, 2020. E-book. Disponível em: www.univates.br/ biblioteca. Acesso em: 18 out. 2020.

PARENTE, Marta Maria de A.; LÜCK, Heloísa. Mapeamento de estruturas de gestão colegiada em escolas dos sistemas estaduais de ensino. Revista Em Aberto, Brasília, v. 17, n. 72, p. 156-162, fev./jun. 2000. Disponível em: http://portal.inep.gov.br/ documents $/ 186968 / 485895 /$ Gest $\% C 3 \% A 3 o+$ escolar+e+forma\%C3\%A7\%C3\%A3o+ de+gestores/3d03dfb4-3a86-4b24-b17f-f140ea58bd45?version=1.3. Acesso em: 13 set. 2020 .

PIAGET, Jean. Para onde vai a educação? Tradução de Ivette Braga. $2^{\mathrm{a}}$ ed. Rio de Janeiro: José Olympio, 1974.

QUEIROZ, Felipe B. Campanuci (org.); OLIVEIRA, Rafael Bastos Costa de. Liberdade para a democracia: considerações sobre a inconstitucionalidade da Escola sem Partido. In: ; PENNA, Fernando; FRIGOTTO, Gaudêncio (orgs). Educação democrática: antídoto ao Escola sem Partido. Rio de Janeiro: UERJ, LPP, 2018, p. 33-50. E-book. Disponível em: https://www.academia.edu/39520119/EDUCA\%C3\%87\%C3\%83O_ DEMOCR\%C3\%81TICA_Ant\%C3\%ADdoto_ao_Escola_sem_Partido. Acesso em: 16 set. 2020.

REZENDE, Ricardo. Horizontes para pensar a universidade comunitária no contemporâneo: 30 teses.... Ijuí: Ed. Unijuí, 2019. E-book. Disponível em: www. univates.br/biblioteca. Acesso em: 17 out. 2020.

SANTOS, Boaventura de Sousa. A universidade no século XXI: para uma reforma democrática e emancipatória da Universidade. $3^{\text {a }}$ ed. São Paulo: Cortez Editora, 2010. 
SCAFF, Elisângela Alves da Silva; PINTO, Isabela Rahal de Rezende. O Supremo Tribunal Federal e a Garantia do Direito à Educação. Revista Brasileira de Educação, Rio de Janeiro, v. 21, n. 65, abr./jun. 2016. Disponível em: https:/ / doi.org/10.1590/ S1413-24782016216523. Acesso em: 18 mar. 2020.

SCHMIDT, João Pedro. Universidades Comunitárias e Terceiro Setor: fundamentos comunitaristas da cooperação em políticas públicas. $1^{\text {a }}$ ed. Santa Cruz do Sul: EDUNISC, 2017.

SCHNECKENBERG, Marisa. A relação entre política pública de reforma educacional e a gestão do cotidiano escolar. Revista Em Aberto, Brasília, v. 17, n. 72, p. 113-124, fev./jun. 2000. Disponível em: http:/ / portal.inep.gov.br/documents/186968/485895/ Gest $\%$ C3\%A3o+escolar+e+forma $\% C 3 \% A 7 \% C 3 \% A 3 o+d e+$ gestores $/ 3 \mathrm{~d} 03 \mathrm{dfb} 4-3 \mathrm{a} 86-$ 4b24-b17f-f140ea58bd45?version=1.3. Acesso em: 13 set. 2020.

SOUZA, Genival Nunes. Gestão Democrática escolar: reflexões e desafios. Dialógica, v. 7, n. 4, 2012. Disponível em: http:/ / cefort.ufam.edu.br/dialogica/files/no7/Vol0704-Gestao_Democratica_Escolar_reflexoes_e_desafios.pdf. Acesso em: 20 set. 2020

TARTUCE, Flávio. Direito Civil: teoria geral dos contratos e contratos em espécie. $15^{\mathrm{a}}$ ed. Rio de Janeiro: Forense, 2020. E-book. Disponível em: www.univates.br/biblioteca. Acesso em: 09 out. 2020. 